\title{
Dossier temático: Ingeniería de tejidos en Odontología*
}

\author{
Thematic Dossier: Tissue Engineering in Dentistry
}

\section{INGRID JOHANNA GARZÓN BELLO}

Universidad de Granada, Granada, España. Igarzon@ugr.es. https://orcid.org/0000-0001-5944$\underline{0578}$

\begin{abstract}
Ana Celeste Ximenes Oliveira
Universidade Federal de Minas Gerais, Belo Horizonte, Brasil. acximenesoliveira@ hotmail.com. https://orcid.org/0000-0003-3079-7172
\end{abstract}

\section{Camilo Durán Correa}

Pontificia Universidad Javeriana, Bogotá, Colombia. camilo.duran@javeriana.edu.co. https://orcid.org/0000-0002-5355-3413

\section{LOREnZA MARía JARAMillo Gómez \\ Pontificia Universidad Javeriana, Bogotá, Colombia. lorenzaj@javeriana.edu.co. https://orcid.org/0000-0002-0087-7879}

*Editorial.

doi: https://doi.org/10.11144/Javeriana.uo37-79.dito 
Cómo citar: Garzón Bello IJ, Ximenes Oliveira AC, Durán Correa C, Jaramillo Gómez LM. Dossier temático: Ingeniería de tejidos en Odontología. Univ Odontol. 2018 jul-dic; 37(79). https://doi.org/10.11144/Javeriana.uo37-79.dito

\section{Palabras clave}

ingeniería de tejidos; odontología

\section{Keywords}

dentistry; tissue engineering

La odontología no se ha marginado de los grandes y rápidos cambios que han tenido las ciencias debido a la globalización. La ingeniería biomédica, la ingeniería de tejidos y la biología molecular, entre otras disciplinas, trabajan conjuntamente para aportar nuevas alternativas terapéuticas que repliquen la anatomía, fisiología y función de los tejidos u órganos afectados por patología, trauma o alteraciones de desarrollo. Este vínculo ha conducido al diseño de nuevos materiales, técnicas de diagnóstico y terapias que ayudan a resolver algunos de los grandes problemas de las ciencias médicas. Para generar soluciones más cercanas al proceso normal de organogénesis, las herramientas de ingeniería y ciencias de la vida se combinan para desarrollar sustitutos bioartificiales de órganos y tejidos que, a su vez, pueden aplicarse en medicina regenerativa y odontología para promover el crecimiento celular y estimular la regeneración de los tejidos. En odontología, las técnicas recientes de ingeniería de tejidos se han aplicado en área como la cirugía maxilofacial, la periodoncia y la endodoncia. Por lo anteriormente expuesto, se invitó a la 
comunidad académica a someter investigaciones originales para el dossier Ingeniería de tejidos en Odontología.

El objetivo de Universitas Odontologica con la publicación del dossier temático en Ingeniería de tejidos en Odontología es proporcionar una revisión rigurosa por pares y de alta calidad de los artículos sometidos para la publicación de la investigación en ingeniería de tejidos y su aplicación clínica. En este contexto y dado que el campo de la ingeniería de tejidos es por su propia naturaleza multidisciplinario, nos interesa publicar trabajos sobre el conocimiento y comprensión de la biología celular, la biofísica, los materiales y biomateriales, y su aplicación en la regeneración de los tejidos de la región oral y craneofacial. Se incluyen en este dossier tres artículos que exploran tres temas interesantes: las políticas gubernamentales en materia de ingeniería tisular en Latinoamérica, los enfoques y métodos empleados para elaborar un biodiente, y las aplicaciones de la fibrina rica en plaquetas en odontología regenerativa. 